\title{
One-Year Follow-up Study Detects Myocardial Changes with Cardiovascular Magnetic Resonance Tagging in Active Rheumatoid Arthritis
}

\section{Lehmonen, Lauri}

2018-04

Lehmonen , L , Vuorinen , A-M , Koivuniemi , R , Leirisalo-Repo , M , Holmström , M M , Kivistö , S \& Kaasalainen , T 2018 , ' One-Year Follow-up Study Detects Myocardial Changes with Cardiovascular Magnetic Resonance Tagging in Active Rheumatoid Arthritis ' , Academic Radiology, vol. 25 , no. 4 , pp. 476-485 . https://doi.org/10.1016/j.acra.2017.10.017

http://hdl.handle.net/10138/310827

https://doi.org/10.1016/j.acra.2017.10.017

cc_by_nc_nd

acceptedVersion

Downloaded from Helda, University of Helsinki institutional repository.

This is an electronic reprint of the original article.

This reprint may differ from the original in pagination and typographic detail.

Please cite the original version. 


\section{One-year follow-up study detects myocardial changes with cardiovascular magnetic resonance tagging in active rheumatoid arthritis}

Lauri Lehmonen $^{1,2, *}$, Aino-Maija Vuorinen ${ }^{1}$, Riitta Koivuniemi ${ }^{3}$, Marjatta Leirisalo-Repo ${ }^{3}$, Miia Holmström $^{1}$, Sari Kivistö ${ }^{1}$ and Touko Kaasalainen ${ }^{1}$

${ }^{1}$ HUS Medical Imaging Center, Radiology, University of Helsinki and Helsinki University Hospital, PO Box 340, Helsinki FI-00029 HUS, Finland

2 2 Department of Physics, University of Helsinki, PO Box 64, Helsinki FI-00014, Finland

3 Rheumatology, University of Helsinki and Helsinki University Hospital, PO Box 372, Helsinki FI-00029 HUS, Finland

* Corresponding author:

Lauri Lehmonen (lauri.lehmonen@helsinki.fi)

HUS Medical Imaging Center, Radiology, University of Helsinki and Helsinki University Hospital, PO Box 340, Helsinki FI-00029 HUS, Finland 


\title{
One-year follow-up study detects myocardial changes with cardiovascular magnetic resonance tagging in active rheumatoid arthritis
}

\author{
ABSTRACT
}

Rationale and objectives: To evaluate the effects of one-year of medical treatment on myocardial function in active rheumatoid arthritis (RA).

Materials and methods: Thirty-nine female RA patients without any known cardiovascular disease underwent a cardiovascular magnetic resonance (CMR) examination before and after one-year of antirheumatic treatment. The population comprised untreated active early RA (ERA) and chronic RA (CRA) patients, which were grouped accordingly. The CMR protocol included volumetric determinations, late gadolinium enhancement imaging, myocardial tagging and native T1 mapping. DAS28-CRP disease activity scores were calculated before and after the treatment.

Results: Results are reported as median (quartile 1 - quartile 3). Time to peak diastolic filling rate improved in ERA (495 (443 - 561) ms vs 441 (340 - 518) ms, p = 0.018). Peak diastolic mean mid short-axis circumferential strain rate of all six segments was improved (82 (74 - 91)\%/s vs $91(77-100) \% / \mathrm{s}, \mathrm{p}=0.05$, particularly in the anterior segment $(82(63-98) \% / \mathrm{s}$ vs $86(77-109) \% / \mathrm{s}, \mathrm{p}=0.013)$. DAS28-CRP decreased in ERA (3.8 (3.2 - 4.1) vs $1.6(1.4-2.2), \mathrm{p}<0.001)$. In CRA, no statistically significant improvement was detected.

Conclusion: Early treatment of active RA is important, as myocardial function detected with CMR tagging improved in ERA in parallel with decreasing inflammatory activity.

Keywords: cardiovascular magnetic resonance imaging, tagging, strain, rheumatoid arthritis.

\section{Introduction}

Rheumatoid arthritis (RA) is a chronic systemic autoimmune disease with common and often subclinical cardiovascular involvement [1]. The mechanisms of myocardial disease in RA are not fully understood but higher prevalence of myocardial fibrosis, diastolic dysfunction or heart failure with normal ejection fraction 
have been documented $[2,3]$. The prevalence of heart failure with normal ejection fraction in RA patients has been reported to be as high as $23 \%$ [4] and the prevalence of predominant diastolic dysfunction to be even higher $(31-66 \%)[5,6]$. Cardiac involvement is assumed to result from a combination of processes, such as chronic inflammation leading to endothelial dysfunction, and increased levels of inflammatory cytokines that lead to the development of myocardial dysfunction [7]. A major contributor to reduced life expectancy in RA patients is coronary heart disease and heart failure [7]. Therefore, early detection of myocardial changes in RA is crucial to ensure early therapeutic intervention.

Global left ventricular ejection fraction (LVEF) and left ventricular filling parameters measured with cardiovascular magnetic resonance (CMR) imaging can be insensitive for the detection and assessment of early changes in myocardial contractility and relaxation [8]. The myocardial contractility and relaxation use strain as a measure of myocardial deformation, and this approach can be assessed with strain echocardiography or CMR tagging. Tagging is considered as the gold standard for non-invasive deformation imaging $[9,10]$. Global circumferential strain assessed by CMR can identify myocardial dysfunction for several conditions that are independent of LVEF $[11,12]$. Recently, global circumferential strain has been shown to have an independent prognostic value in both asymptomatic patients and those with heart failure [13]. For non-invasive evaluation of diffuse myocardial inflammation and fibrosis, native T1 mapping has become a promising CMR tool. Decreased native T1 values have been identified in myocardial iron overload states or glycosphingolipid accumulation in Anderson-Fabry disease, whereas high native T1 values have been related to myocardial inflammation, fibrosis, amyloid accumulation, and other conditions [14]. The influence of active RA and the effects of medical treatment with synthetic and biological disease modifying drugs (DMARDs) were our area of interest in this one-year follow-up study. 


\section{Materials and methods}

Study population

The 39 patients of this study (Table 1) were selected from a previous study population of 60 patients that had active RA [2]. To minimize the risk of a patient having any other disorder than RA that could damage the myocardium, the study population comprised non-smoking, non-diabetic females under the age of 70 who had no history of heart disease, renal failure, thyrotoxicosis or untreated hypertension and who had no severe obesity. There were two patient groups: patients with untreated active early RA (ERA) who started conventional synthetic disease modifying antirheumatic drugs (csDMARDs) and patients with chronic RA (CRA) who had had inadequate response to csDMARDs and were candidates for biological treatment (bDMARDs). The 39 RA patients had successfully undergone CMR examinations with sufficient image quality for reliable analyses of tagging and native T1 images before and after the one-year DMARD treatment period. RA disease activity score DAS28-CRP was assessed before and after the treatment period. All 60 patients had two CMR examinations (total of 120) out of which 21 had insufficient image quality for quantitative analysis. These studies had severe cardiac gating and breathing induced image artefacts in either the native $\mathrm{T} 1$ images or strain tagging images. Thus, these studies were excluded from analysis and only patients with all $\mathrm{T} 1$ and strain results were included in the study.

The study was approved by the local ethics review board and a written consent was obtained from each participating patient before the study commenced.

\section{Table 1}

CMR examination

The CMR protocol was identical for each patient before and after the one-year treatment period. The CMR studies were performed using either 3T (23 patients) or 1.5T (16 patients) systems (Verio and Avanto ${ }^{\text {fit }}$, 
Siemens Healthcare, Germany, respectively) with a 32-channel cardiac coil. The use of two scanner systems was due to the availability of the T1 mapping sequence at our institution (before 2014: 3T; after: 1.5T). Each patient was imaged using the same scanner before and after the treatment. The imaging protocol included complete stacks of long-axis (4-chamber view) and short-axis cine images, strain tagging, conventional late gadolinium enhancement (LGE) imaging and native mid-ventricular short-axis T1 mapping. The complete acquisition and analysis procedure excluding the strain tagging sequences has been described in a previous study [2]. Tagging analysis was performed only recently and thus not described before.

The strain tagging sequences were performed at the mid-ventricular levels for both long-axis and short-axis directions using prospective cardiac gating and breath hold to minimize motion artefacts. The sequence used was a typical spatial modulation of magnetization sequence with TR/TE $=33.7 / 4.1 \mathrm{~ms}$, flip angle of $14^{\circ}$, matrix size of $256 \times 256$, slice thickness of $6 \mathrm{~mm}$ and the number of phases 20-25.

Image analysis

The volumetric studies and LGE images were read in consensus by two experienced radiologists each of whom had over 10 years of experience. The T1 analysis was performed by a qualified medical physicist and, the strain tagging segmentation in consensus by a physicist and a radiologist in training. Additionally, the strain image segmentation was verified by a radiologist with over 10 years of experience. The volumetric studies and T1 mapping analyses were performed using QMass MR Software (version 7.6., Medis Medical Imaging Systems, Leiden, Netherlands) and the strain tagging analysis using Segment software v.2.0 R5030 (http://segment.heiberg.se) $[15,16]$. The T1 mapping and short-axis strain tagging analyses were both performed for each of six segments in the mid short-axis level of the left ventricle. The boundaries of the tagged mid short-axis left ventricle were drawn using the manual segmentation tools of Segment for the strain tagging analysis. The segmentation was performed in one of the first five images of the image sequence (Fig. 1) and the software analyzed the rest of the images semi-automatically. The strain tagging analysis resulted in calculation of segmental circumferential and longitudinal strain (\%) curves as a function 
of time (ms), which covered the whole cardiac cycle. We focused on the analysis of segmental circumferential peak mid short-axis and peak mean long-axis strain parameters.

\section{Fig. 1}

The strain data of each segment was used to derive the mean time derivative, i.e. the strain rate of the corresponding strain. The derivatives were computed using a custom function that utilizes the "diff-function" in MATLAB R2016A (The MathWorks, Inc., Natick, MA, USA). The segmental peak short-axis systolic strain and diastolic strain rate were then determined as the momentary maximum value of the curves (Fig. 2). In the long-axis direction, the peak mean systolic strain and diastolic strain rate were calculated as the mean value across all seven long-axis segments. Strain values were analyzed per segment in the short-axis direction and as a mean in the long-axis direction. This difference in approach was because short-axis systolic strain and diastolic strain rates were compared with the corresponding T1 relaxation times to find correlations, whereas no long-axis T1 values were available. The values of peak systolic strain were negative, thus, a change was considered positive when the value of strain was more negative after the treatment than before the treatment.

Fig. 2

Statistical analysis

All the acquired results were compared separately for ERA and CRA patients and were presented as median and quartile 1 - quartile 3 (Q1 - Q3). Continuous variables were compared before and after one-year of DMARD treatment using the Wilcoxon signed-rank test. Pearson and Spearman correlations were used to estimate statistical correlations between the changes in $\mathrm{T} 1$ relaxation times and the changes in peak diastolic strain rate for both groups in the short-axis direction. Pearson and Spearman correlations were also used to test correlations between the changes in DAS28-CRP and the changes in peak diastolic strain rates for the short-axis and long-axis directions for both groups. The peak mean systolic strain was additionally compared 
with the peak mean diastolic strain rate. The statistical tests used were two-sided and p-values $<0.05$ were considered statistically significant. Statistical analyses were performed using MATLAB R2016A.

\section{Results}

Volumetric findings

The median time to peak filling rate shortened (495 (443 - 561) ms vs $441(340-518) \mathrm{ms}, \mathrm{p}=0.018)$ and DAS28-CRP improved ERA (3.8 (3.2 - 4.1) vs $1.6(1.4-2.2), \mathrm{p}<0.001)$ for the ERA patients (Table 2). Left ventricle end-diastolic volume decreased among CRA patients $\left(81(74-92) \mathrm{ml} / \mathrm{m}^{2}\right.$ vs $77(72-87) \mathrm{ml} / \mathrm{m}^{2}, \mathrm{p}=$ 0.031) (Table 3). No other significant changes were found in either group.

Table 2

\section{Table 3}

Strain tagging findings

The peak diastolic short-axis strain rate for ERA patients (Table 4) improved (82 (74 - 91)\%/s vs 91 (77 100) $\% / \mathrm{s}, \mathrm{p}=0.05)$, particularly in the anterior segment $(82(63-98) \% / \mathrm{s}$ vs $85(77-109) \% / \mathrm{s}, \mathrm{p}=0.013)$. The mean long-axis diastolic strain rate did not improve significantly for either group. The systolic strain changes were statistically not significant in either group (Table 5).

\section{Table 4}

\section{Table 5}

LGE findings 
Before starting the DMARD treatment, LGE was detected in 17 out of $25(68 \%)$ ERA patients and in 8 out of 14 (57\%) CRA patients. After one-year of DMARD treatment, LGE was observed in 19 out of the 25 (76\%) ERA patients and 8 out of 14 (57\%) CRA patients. Fig. 3 shows the distribution of the LGE detected in both groups following the 17-segment model of the left ventricle by the American Heart Association [17].

\section{Fig. 3}

LGE was detected mainly in the septal, inferior and inferolateral segments in basal and mid-ventricular levels of the left ventricle in both groups. No LGE was detected in apical segments in any of the patients. LGE was typically subepicardial, midmyocardial or patchy in both groups. LGE did not change significantly in either group during treatment.

T1 findings and correlation

Median changes in the T1 relaxation times varied from +25 to $-53 \mathrm{~ms}$ in ERA and from +33 to $-47 \mathrm{~ms}$ in CRA (appendix Tables A1 and A2). The T1 relaxation times, segmental or mean, did not change significantly in either group. Changes in T1 relaxation showed no correlation with changes in short-axis or long-axis peak diastolic strain rate in either group.

\section{Correlation with DAS28-CRP}

Changes in DAS28-CRP correlated with the changes in mean mid short-axis peak diastolic strain rate in ERA (Fig. 4) but not for the CRA group (data not shown). The correlation was negative $(\mathrm{R}=-0.46, \mathrm{p}=$ 0.026) and thus, the DAS28-CRP decreased as the peak mean mid short-axis diastolic strain rate improved. The change in DAS28-CRP did not correlate with the change in peak diastolic long-axis strain rate or peak systolic short-axis strain in either group. 
Fig. 4

Correlation of the changes in peak systolic strain and peak diastolic strain rate

Statistically strong correlations were detected between the changes in peak mean short-axis systolic strain and peak mean short-axis diastolic strain rate in the entire study population of 39 RA patients. A similar correlation was also found in the long-axis direction (Fig. 5).

\section{Fig 5}

\section{Discussion}

The current work is the first prospective follow-up study that assesses the effects of active RA and DMARD treatment targeting to remission on myocardial function that has been evaluated with CMR tagging. We found statistically significant improvement in diastolic myocardial function in the newly diagnosed group after one-year csDMARD treatment. Time to peak diastolic filling rate and peak diastolic circumferential short-axis strain rate improved in this group. Systolic strain did not change significantly in either group, regardless, changes in peak systolic strain correlated with the changes in diastolic strain rate in the entire study population (Fig 5). Myocardial involvement and diastolic dysfunction have been reported to be common in RA patients free of any clinical cardiovascular disease [2,4,5]. Increased prevalence of diastolic heart failure in patients with RA is suggested to correlate with RA disease activity but not with the treatment type [18]. Generally, changes in the LV function and structure are known to correlate with a higher risk of cardiovascular mortality [19]. However, an active antirheumatic treatment and thus a decrease in RA disease activity may also inhibit the progression of myocardial involvement [20].

Left ventricle end-diastolic volume decreased slightly in chronic patients. Although diastolic strain rate decreased in all segments no significant changes or any improvement in the myocardial function was found in CRA after one-year treatment with bDMARDs. On the other hand, evidence does exists that reduced 
systolic tissue velocities occur in diastolic heart failure, as systole and diastole are closely interdependent [21]. Several physiological variables simultaneously affect left ventricular filling and may thus have confounding effects on the ventricular inflow [22]. CMR tagging and ultrasonography-based speckle tracking are less sensitive to these pre- and afterload changes [23]. Therefore, CMR tagging might be an accurate method in the detection of early myocardial changes in diastolic dysfunction. In the present study, the peak systolic circumferential mid short-axis strain was within normal range in both ERA and CRA while the peak systolic longitudinal strain was normal in ERA and slightly reduced in CRA [24,25]. RA disease activity of the ERA patients as measured by DAS28-CRP score, was reduced after the one-year treatment with csDMARD. This change in disease activity associated with the changes in mean short-axis diastolic strain rate (Fig. 4) is in line with previous studies $[18,26]$. Contrary to ERA patients, disease activity did not improve in the CRA group. It is plausible that this lack of improvement is partly due to this group having had the chronic active disease for a mean of 17.3 years.

Native T1 values showed no statistically significant change within the follow-up period. Furthermore, individual T1 values showed no correlation to circumferential peak diastolic strain rate in either group. We found a correlation between the mid-ventricular short-axis strain and T1 relaxation time at 1.5T in both ERA $(\mathrm{n}=14, \mathrm{R}=0.61, \mathrm{p}=0.03)$ and CRA $(\mathrm{n}=18, \mathrm{R}=0.55, \mathrm{p}=0.04)$ patients' studies. These correlations are in line with the previous results reported by Ntusi et al [24]. Comparing with recent studies of healthy myocardial $\mathrm{T} 1$ relaxation times $[27,28]$ our patients imaged at $1.5 \mathrm{~T}(\mathrm{n}=16)$ had elevated $\mathrm{T} 1$ relaxation times whereas patients imaged at $3 \mathrm{~T}(\mathrm{n}=23)$ did not. An increase of native $\mathrm{T} 1$ relaxation time is reported to associate with myocardial inflammation or fibrosis. T1 mapping, therefore, seems to be a good method for detecting diffuse myocardial fibrosis, whereas conventional LGE imaging is useful for assessing local scarring [26]. A higher prevalence of myocardial fibrosis, inflammation and positive LGE findings in RA patients have been reported and all these parameters may contribute to higher native T1 values [29]. LGE was found in $64 \%$ before and in $69 \%$ of our patient population after the one-year follow-up period. Accurate distinction of the underlying causes of elevated $\mathrm{T} 1$ levels is not possible using native T1 myocardial relaxation times without post-contrast T1 mapping and extracellular volume calculations [14]. The local scarring areas may affect $\mathrm{T} 1$ relaxation times directly, whereas acute inflammation may convert into fibrosis 
over time. Both these explanations may contribute to the fact that we found no statistically significant changes in $\mathrm{T} 1$ relaxation times during the one-year follow-up in our patients.

Both 3T and 1.5T MRI scanners were used in this study for image acquisition. Native T1 relaxation time is prolonged in higher magnetic fields so the absolute T1 values are not comparable for the two MRI systems used in our study. The strength of the magnetic field may also have impact on the changes of T1 values as T1 relaxation time increases in non-linear fashion as the magnetic field strength increases [30]. At 3T, we found no correlation between $\mathrm{T} 1$ and mid-ventricular short-axis strain. This could indicate that myocardial strain might also be nonlinearly affected by the increasing magnetic field strength similarly to $\mathrm{T} 1$ relaxation. Recently, variations of global circumferential strain with CMR feature tracking in different studies were specifically associated to differences in magnetic field strength [31]. Strain values have also been shown to differ at $1.5 \mathrm{~T}$ and $3 \mathrm{~T}[32]$.

\section{Limitations}

The study groups for this work were part of a larger group of patients that had been selected on image quality grounds, to enable reliable quantitative analysis. This reduced our group of ERA patients to 25 individuals and CRA patients to only 14 subjects. Myocardial function is known to depend on age, sex and physical activity [33], the small sample size of CRA patients may therefore explain our inability to find statistically significant changes. The size of our study population also prevented us from dividing ERA and CRA patients into subgroups based on magnetic field strength of the MRI system used.

\section{Conclusion}

Diastolic myocardial function is affected in the course of RA. Therefore, early antirheumatic treatment in the targeting of active RA to remission can maintain or improve diastolic myocardial function. These findings may emphasize the importance of effective treatment of RA not only for preventing joint destruction, but also for preventing concomitant myocardial damage. 


\section{Conflict of interest: None.}

Informed consent: Written informed consent was obtained from all individual participants included in the study.

\section{References}

1. Mavrogeni S, Dimitroulas T, Sfikakis PP, Kitas GD (2013) Heart involvement in rheumatoid arthritis: multimodality imaging and the emerging role of cardiac magnetic resonance. Semin Arthritis Rheum 43 (3):314-324. doi:10.1016/j.semarthrit.2013.05.001

2. Holmstrom M, Koivuniemi R, Korpi K, Kaasalainen T, Laine M, Kuuliala A, Leirisalo-Repo M, Kupari M, Kivisto S (2016) Cardiac magnetic resonance imaging reveals frequent myocardial involvement and dysfunction in active rheumatoid arthritis. Clin Exp Rheumatol 34 (3):416-423

3. Aslam F, Bandeali SJ, Khan NA, Alam M (2013) Diastolic dysfunction in rheumatoid arthirits: a metaanalysis and systematic review. Arhritis Care Res (Hoboken) 65 (4):534-543

4. Kobayashi Y, Giles JT, Hirano M, Yokoe I, Nakajima Y, Bathon JM, Lima JA, Kobayashi H (2010) Assessment of myocardial abnormalities in rheumatoid arthritis using a comprehensive cardiac magnetic resonance approach: a pilot study. Arthritis Res Ther 12 (5):R171. doi:10.1186/ar3131

5. Liang KP, Myasoedova E, Crowson CS, Davis JM, Roger VL, Karon BL, Borgeson DD, Therneau TM, Rodeheffer RJ, Gabriel SE (2010) Increased prevalence of diastolic dysfunction in rheumatoid arthritis. Ann Rheum Dis 69 (9):1665-1670. doi:10.1136/ard.2009.124362

6. Gonzales-Juanatey C, Testa A, Garcia-Castelo A, Garcia-Porrua C, Llorca J, Ollier WE, Gonzalez-Gay MA (2004) Echocardiographic and Doppler findings in long-term treated rheumatoid arthritis patients without clinically evident cardiovascular disease. Semin Arthritis Rheum 33 (4):231-238

7. Giles JT, Fernandes V, Lima JA, Bathon JM (2005) Myocardial dysfunction in rheumatoid arthritis: epidemiology and pathogenesis. Arthritis Res Ther 7 (5):195-207. doi:10.1186/ar1814

8. Buckberg G, Hoffman JI, Mahajan A, Saleh S, Coghlan C (2008) Cardiac mechanics revisited: the relationship of cardiac architecture to ventricular function. Circulation 118 (24):2571-2587.

doi:10.1161/CIRCULATIONAHA.107.754424

9. Shehata ML, Cheng S, Osman NF, Bluemke DA, Lima JA (2009) Myocardial tissue tagging with cardiovascular magnetic resonance. J Cardiovasc Magn Reson 11 (55):55. doi:10.1186/1532-429X-11-55

10. Wu L, Germans T, Guclu A, Heymans MW, Allaart CP, van Rossum AC (2014) Feature tracking compared with tissue tagging measurements of segmental strain by cardiovascular magnetic resonance. $\mathrm{J}$ Cardiovasc Magn Reson 16 (10):10. doi:10.1186/1532-429X-16-10

11. Choi EY, Rosen BD, Fernandes VR, Yan RT, Yoneyama K, Donekal S, Opdahl A, Almeida AL, Wu CO, Gomes AS, Bluemke DA, Lima JA (2013) Prognostic value of myocardial circumferential strain for incident heart failure and cardiovascular events in asymptomatic individuals: the Multi-Ethnic Study of Atherosclerosis. Eur Heart J 34 (30):2354-2361. doi:10.1093/eurheartj/eht133

12. Cho GY, Marwick TH, Kim HS, Kim MK, Hong KS, Oh DJ (2009) Global 2-dimensional strain as a new prognosticator in patients with heart failure. J Am Coll Cardiol 54 (7):618-624 
13. Mordi I, Bezerra H, Carrick D, Tzemos N (2015) The Combined Incremental Prognostic Value of LVEF, Late Gadolinium Enhancement, and Global Circumferential Strain Assessed by CMR. JACC Cardiovasc Imaging 8 (5):540-549. doi:10.1016/j.jcmg.2015.02.005

14. Schelbert EB, Messroghli DR (2016) State of the Art: Cinical Applications of Cardiac T1 Mapping. Radiology 278 (3):658-676

15. Heiberg E, Sjögren J, Ugander M, Carlsson M, Engblom H, Arheden H (2010) Desing and Validation of Segment - a Freely Available Software for Cardiovascular Image Analysis. BMC Medical Imaging 10 (1)

16. Morais P, Heyde B, Barbosa D, Queirós S, Claus P, D'Hooge J Cardiac motion and deformation estimation from tagged MRI sequences using temporal coherent image registration framework. In: Proceedings of the meeting on Functional Imaging and Modelling of the Heart (FIMH), Lecture notes in Computer Science vol 7945, London, 2013.

17. Cerqueira MW, N.; Dilsizian, V.; Jacobs, A.; Kaul, S.; Laskey, W.; Pennel, D.; Rumberger, J. Ryan, T. (2002) Standardized Myocardial Segmentation and Nomenclature for Tomographic Imaging of the Heart. Circulation 105:539-542. doi:10.1161/hc0402.102975

18. Schau T, Gottwald M, Arbach O, Seifert M, Schöpp M, M.Neuß, Butter C, Zänker M (2015) Increased Prevalence of Diastolic Heart Failure in Patients with Rheumatoid Arthritis Correlates with Active Disease, but Not with Treatment Type. J Rheumatol 42 (11):2029-2037

19. Corrao S, Messina S, Pistone G, Calvo L, Scaglione R, Licata G (2013) Heart involvement in rheumatoid arthritis: systematic review and meta-analysis. Int J Cardiol 167 (5):2031-2038.

doi:10.1016/j.ijcard.2012.05.057

20. Kobayashi Y, Kobayashi H, Hirano M, Giles JT (2014) Left ventricular regional dysfunction using cardiac magnetic resonance imaging in rheumatoid arthritis patients without cardiac symptoms: comparison between methotrexate and biologics treatment groups. J Rheumatol 41 (7):1560-1562

21. Leong DP, Pasquele CGD, Selvanayagam JB (2010) Heart Failure With Normal Ejection Fraction: The Comlementary Roles of Echocardiography and CMR Imaging. JACC Cardiovasc Imaging 3 (4)

22. Ommen SR, Nishimura RA, Appleton CP, Miller FA, Oh JK, Redfield MM, Tajik AJ (2000) Clinical utility of doppler echocardiography and tissue doppler imaging in the estimation of left ventricular filling presures. A comparative simultaneous doppler-catheterization study. Circulation 102:1788-1794

23. Garcia MJ, Thomas JD, Klein AL (1998) New Doppler echocardiographic applications for the study of diastolic function. Journal of the American College of Cardiology 32 (4):865-875. doi:10.1016/s07351097(98)00345-3

24. Venkatesh BA, Donekal S, Yoneyama K, Wu C, Fernandes VR, Rosen BD, Shehata ML, McClelland R, Bluemke DA, Lima JA (2015) Regional myocardial functional patterns: Quantitative tagged magnetic resonance imaging in an adult population free of cardiovascular risk factors: The multi-ethnic study of atherosclerosis (MESA). J Magn Reson Imaging 42 (1):153-159. doi:10.1002/jmri.24749

25. Cupps BP, Taggar AK, Reynolds LM, Lawton JS, Pasque MK (2010) Regional myocardial contractile function: multiparametric strain mapping. Interact Cardiovasc Thorac Surg 10 (6):953-957. doi:10.1510/icvts.2009.220384

26. Ntusi NA, Piechnik SK, Francis JM, Ferreira VM, Matthews PM, Robson MD, Wordsworth PB, Neubauer S, Karamitsos TD (2015) Diffuse Myocardia Fibrosis and Inflammation in Rheumatoid Arthritis: Insights From CMR T1 Mapping. JACC Cardiovasc Imaging 8 (5):526-536 
27. Piechnik SK, Ferreira VM, Lewandowski AJ, Ntusi NA, Banerjee R, Holloway C, Hofman MB, Sado DM, Maestrini V, White SK, Lazdam M, Karamitsos T, Moon JC, Neubauer S, Leeson P, Robson MD (2013) Normal variation of magnetic resonance T1 relaxation times in the human population at $1.5 \mathrm{~T}$ using ShMOLLI. J Cardiovasc Magn Reson 15 (13):13. doi:10.1186/1532-429X-15-13

28. Liu S, Han J, Nacif MS, Jones J, Kawel N, Kellman P, Sibley CT, Bluemke DA (2012) Diffuse myocardial fibrosis evaluation using cardiac magnetic resonance T1 mapping: sample size considerations for clinical trials. J Cardiovasc Magn Reson 14 (90):90. doi:10.1186/1532-429X-14-90

29. Dall'Armellina E, Piechnik SK, Ferreira VM, Si QL, Robson MD, Francis JM, Cuculi F, Kharbanda RK, Banning AP, Choudhury RP, Karamitsos TD, Neubauer S (2012) Cardiovascular magnetic resonance by non contrast T1-mapping allows assessment of severity of injury in acute myocardial infarction. J Cardiovasc Magn Reson 14 (15). doi:10.1186/1532-429X-14-15

30. Gomori JM, Grossman RI, Yu-Ip C, Asakura T (1987) NMR relaxation times of blood: dependence on field strength, oxidation state, and cell integrity. J Comput Assist Tomogr 11 (4):684-690

31. Vo HQ, Marwick TH, Negishi K (2017) MRI-Derived Myocardial Strain Measures in Normal Subjects. JACC Cardiovasc Imaging. doi:10.1016/j.jcmg.2016.12.025

32. Mangion K, Clerfond G, McComb C, Carrick D, Rauhalammi SM, McClure J, Corcoran DS, Woodward R, Orchard V, Radjenovic A, Zhong X, Berry C (2016) Myocardial strain in healthy adults across a broad age range as revealed by cardiac magnetic resonance imaging at 1.5 and 3.0T: Associations of myocardial strain with myocardial region, age, and sex. J Magn Reson Imaging 44 (5):1197-1205.

doi:10.1002/jmri.25280

33. Yoneyama K, Gjesdal O, Choi EY, Wu CO, Hundley WG, Gomes AS, Liu CY, McClelland RL, Bluemke DA, Lima JA (2012) Age, sex, and hypertension-related remodeling influences left ventricular torsion assessed by tagged cardiac magnetic resonance in asymptomatic individuals: the multi-ethnic study of atherosclerosis. Circulation 126 (21):2481-2490. doi:10.1161/CIRCULATIONAHA.112.093146 
Table 1 Baseline clinical features of RA patients. Data expressed as mean \pm standard deviation. *RA $=$ rheumatoid arthritis, $\mathrm{RF}=$ rheumatoid factor, $\mathrm{ACPA}=$ anti-citrullinated peptide antibody, DAS28-CRP = disease activity score, $\mathrm{CRP}=\mathrm{C}$-reactive protein, $\mathrm{LDL}=$ low density lipoprotein, $\mathrm{BMI}=$ body mass index.

Fig. 1 Mid- ventricular short-axis (left) and long-axis (right) tagging images with endocardial and epicardial segmentation

Fig. 2 Example curves demonstrating the mid short-axis strain (left) and strain rate (right). The bold arrow depicts peak systolic strain and the dashed arrow peak diastolic strain rate.

Table 2 Volumetric results for ERA patients $(\mathrm{n}=25)$. Results are expressed as median (Q1 - Q3). *BSA = body surface area, LVESV = left ventricle end-systolic volume, $\mathrm{LVEF}=$ left ventricle ejection fraction, PFR $=$ peak filling rate, TPFR $=$ time to peak filling rate, $\mathrm{DAS} 28-\mathrm{CRP}=\mathrm{RA}$ disease activity score, *statistically significant difference

Table 3 Volumetric results for CRA patients $(\mathrm{n}=14)$. Results are expressed as median $(\mathrm{Q} 1$ - Q3). *Abbreviations are as in table 2.

Table 4 Results of strain tagging analysis for ERA patients $(n=25)$. Results are expressed as median $(\mathrm{Q} 1$ Q3) *SA = short-axis, LA = long-axis, *statistically significant change

Table 5 Results of strain tagging analysis for CRA patients $(n=14)$. Results are expressed as median (Q1 Q3). *SA = short-axis, $\mathrm{LA}=$ long-axis.

Fig. 3 Results for LGE for both groups. Numbers indicate the number of patients with LGE in the segment in question. Upper row: ERA $(n=25)$. Bottom row: CRA $(n=14)$

Fig. 4 Correlation with the change in DAS28-CRP and mean mid short-axis diastolic strain rate for ERA (n $=25), \mathrm{SA}=$ short axis

Fig 5 Correlations between the changes in peak mean systolic strain and peak mean diastolic strain rate in short-axis (SA) (left) and long-axis (LA) (right) directions in the entire study population $(n=39)$

Appendix

Table A1 Results of mid short-axis T1 analysis for 25 ERA patients ( $n=7$ for $1.5 T$ and $n=18$ for $3 T$ ). Results are expressed as median (Q1 - Q3).

Table A2 Results of mid short-axis T1 analysis for 14 CRA patients ( $n=9$ for $1.5 \mathrm{~T}$ and $\mathrm{n}=5$ for $3 \mathrm{~T})$. Results are expressed as median (Q1 - Q3). 

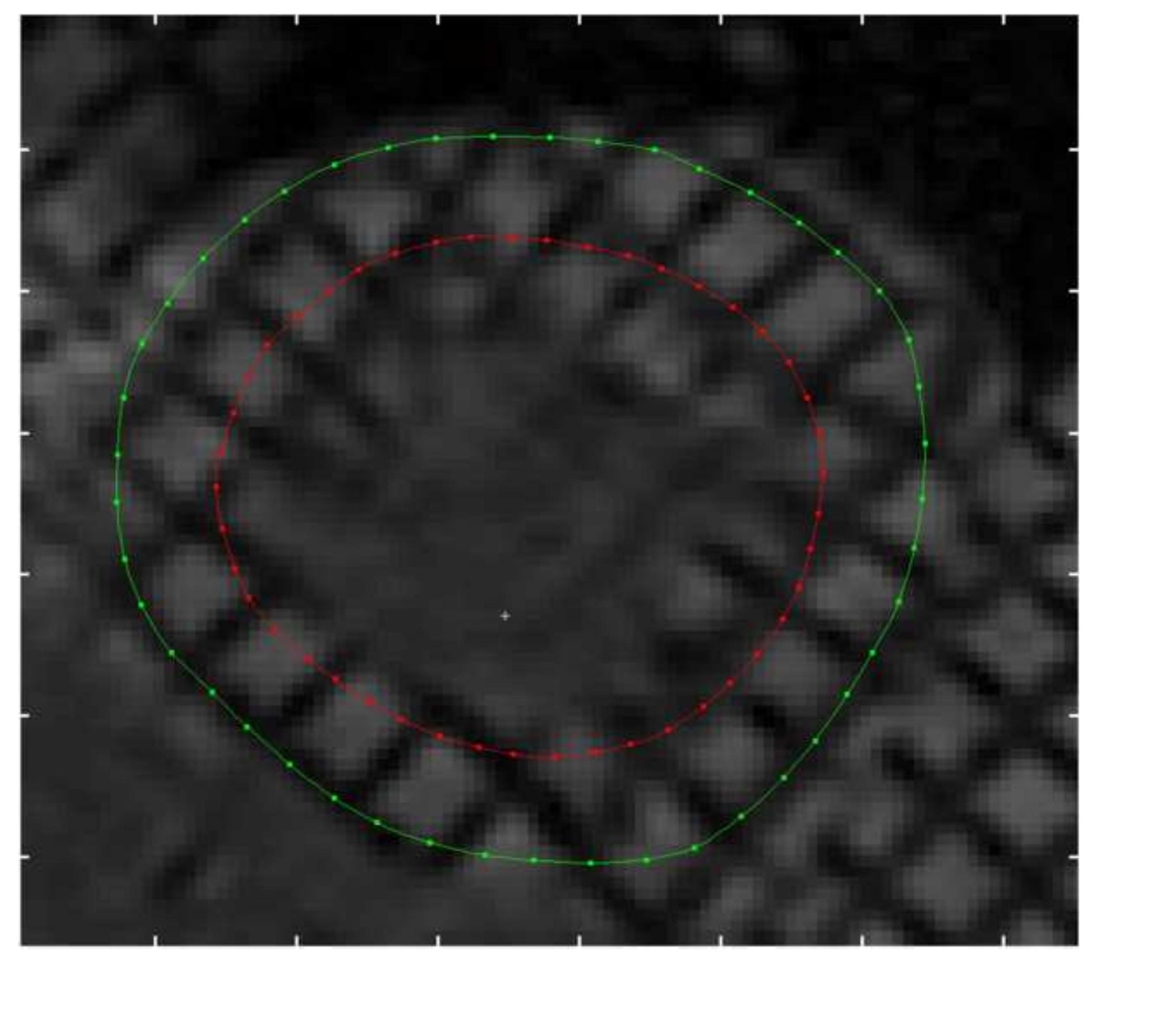

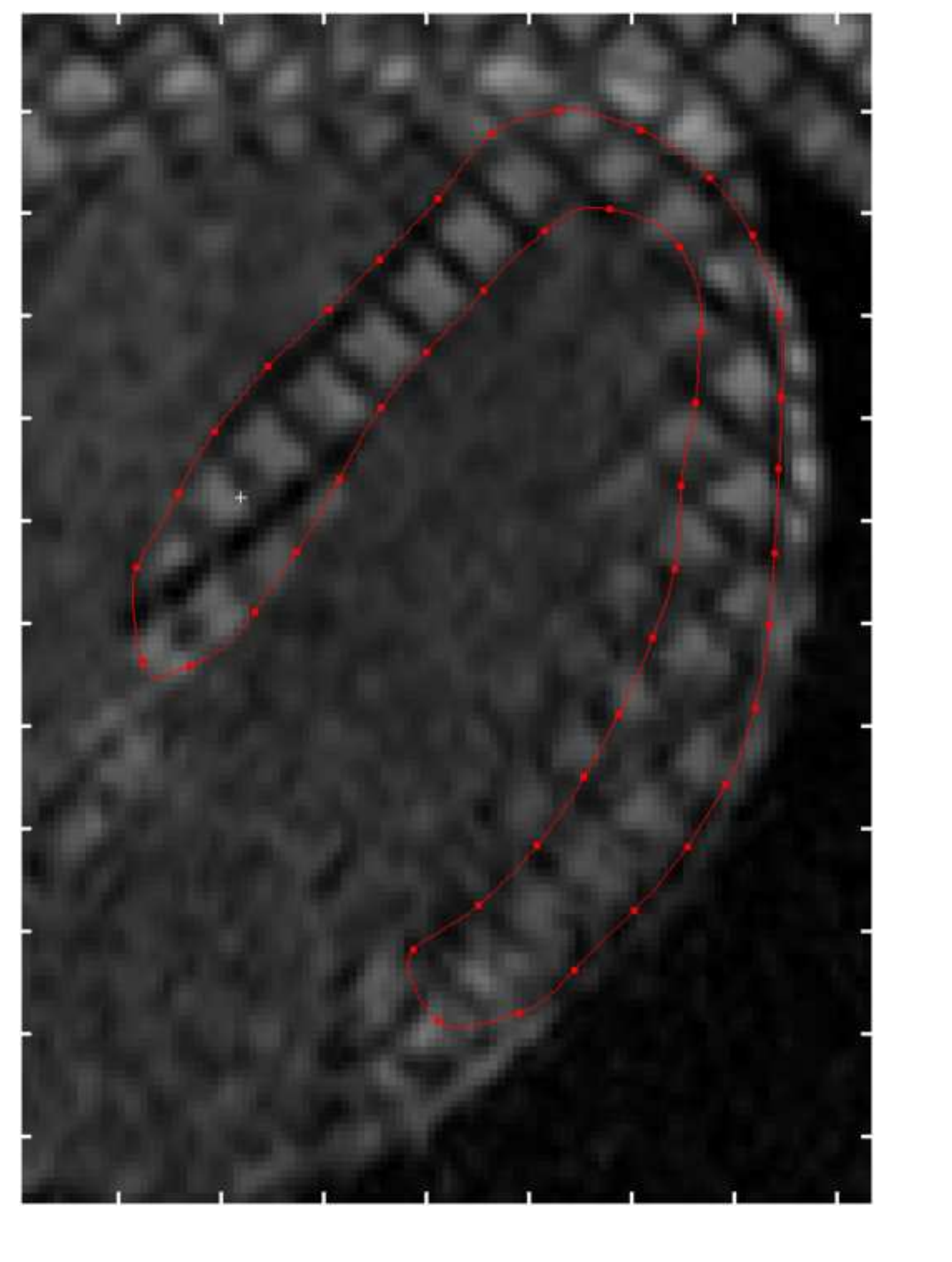
Figure2_left

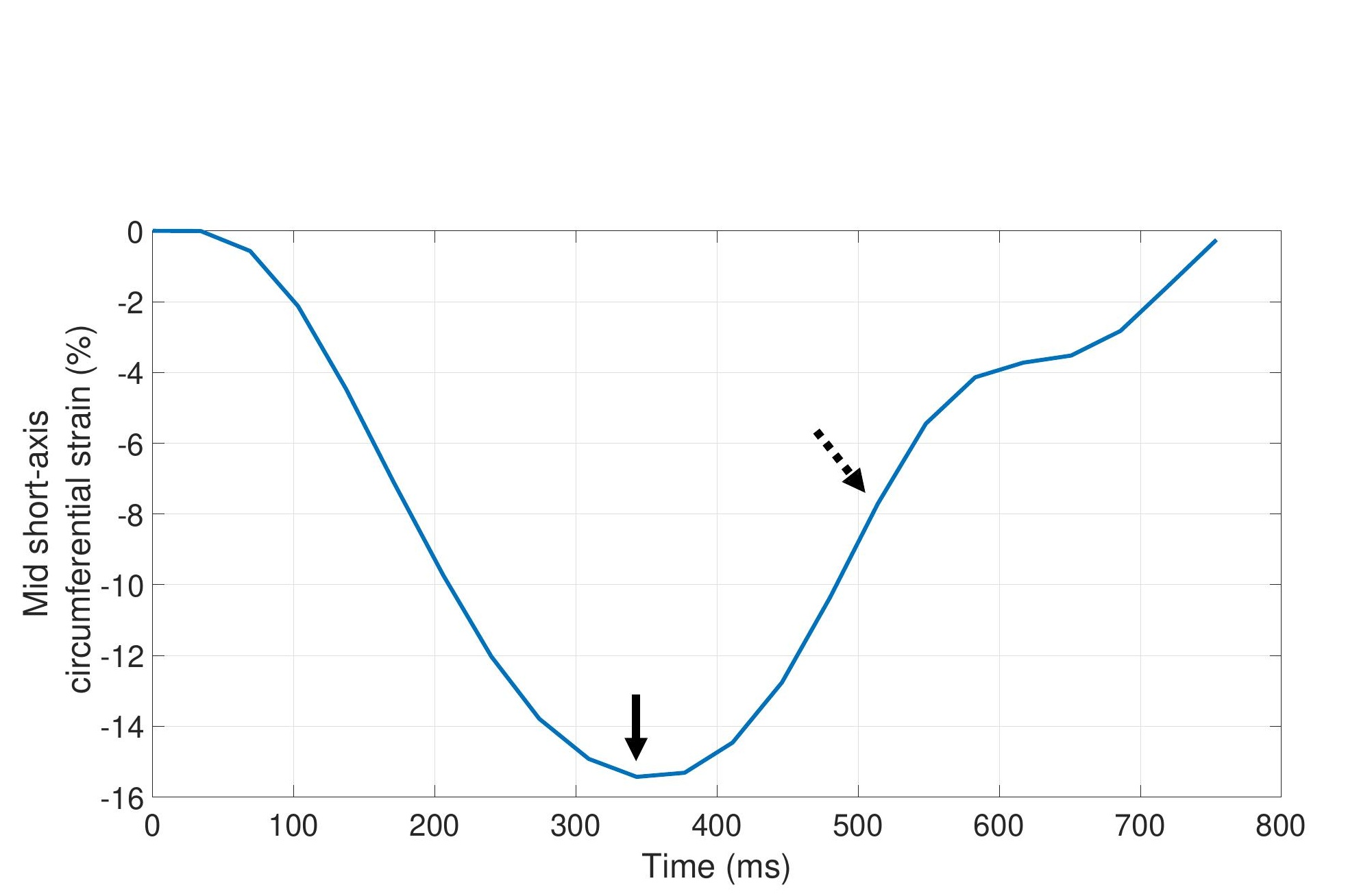
Figure2_eft 
ERA

Before treatment

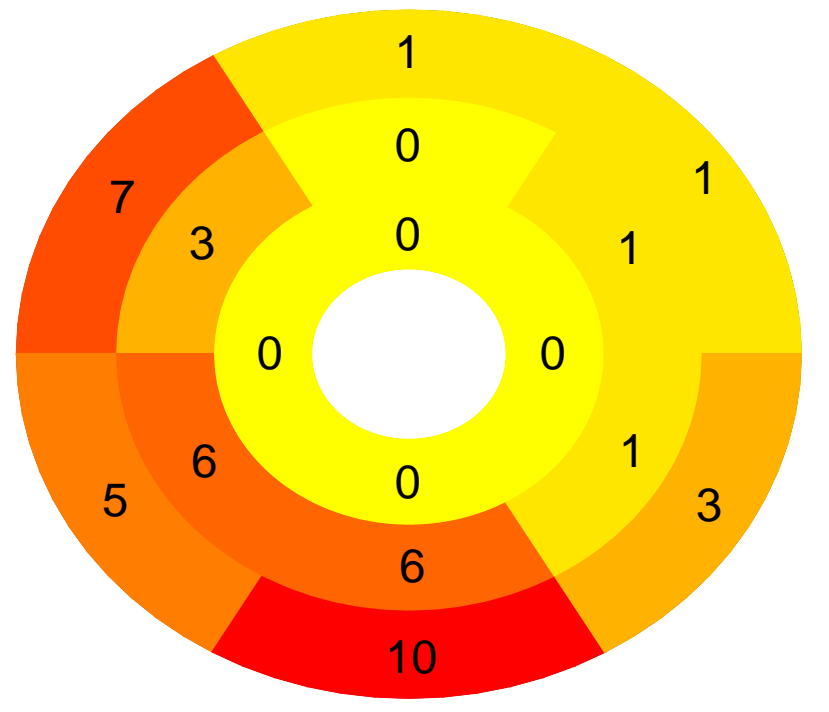

CRA

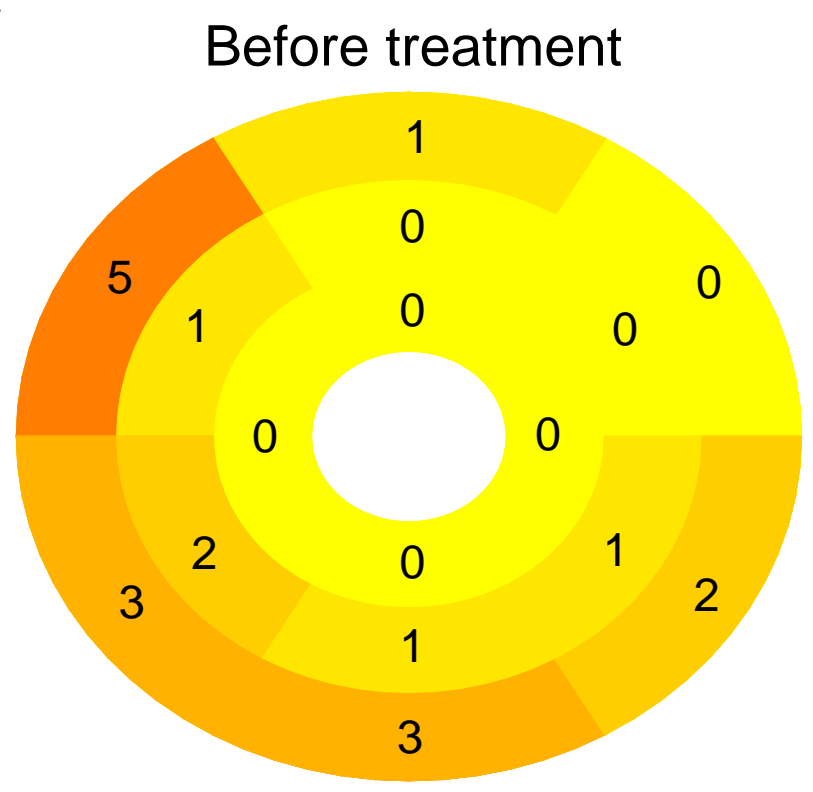

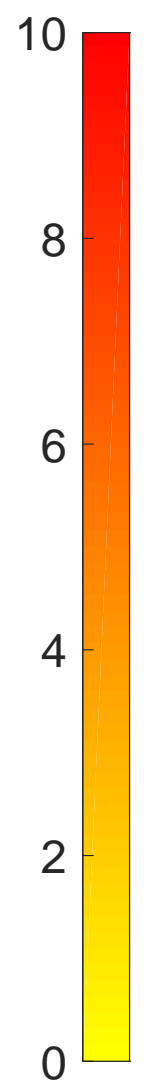

After treatment

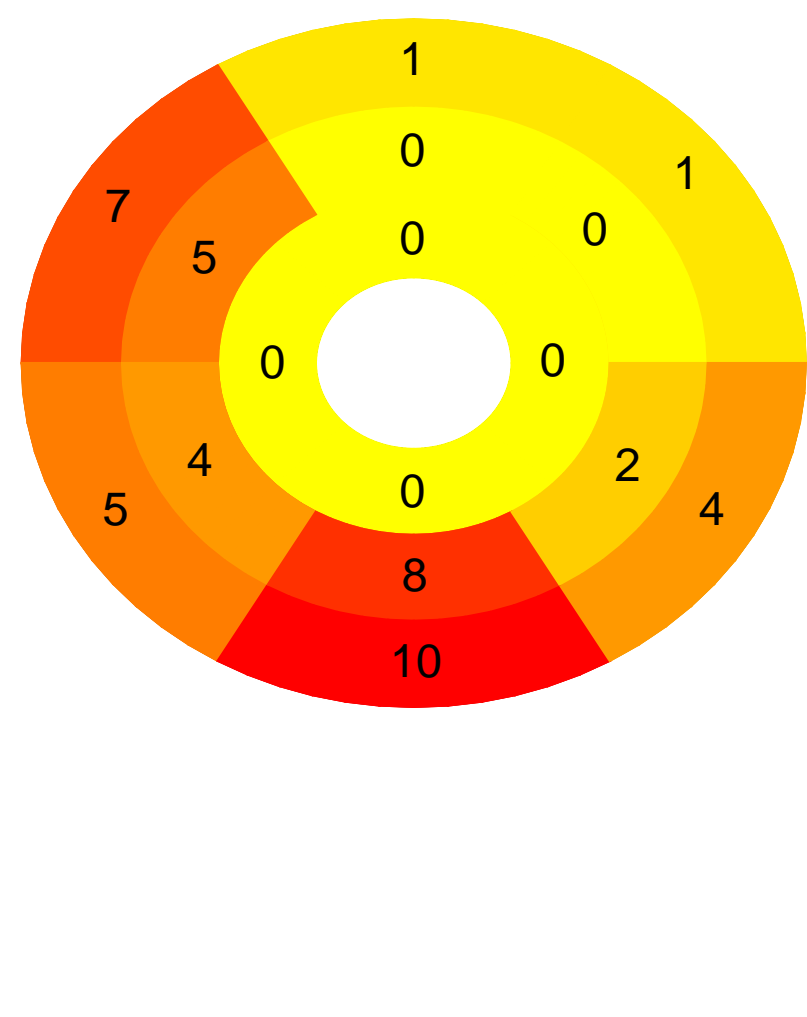

After treatment

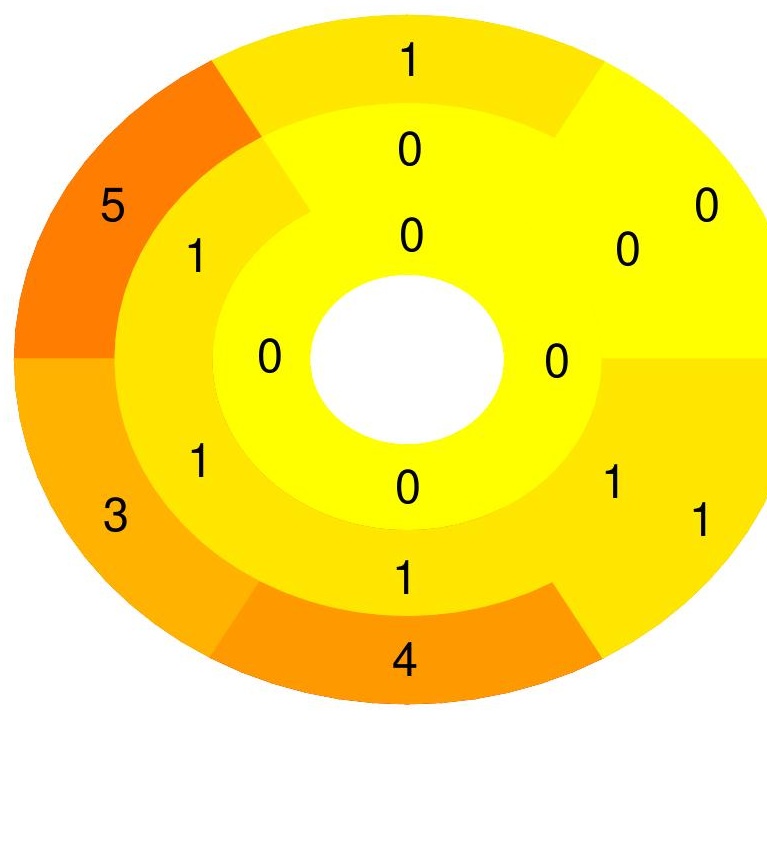




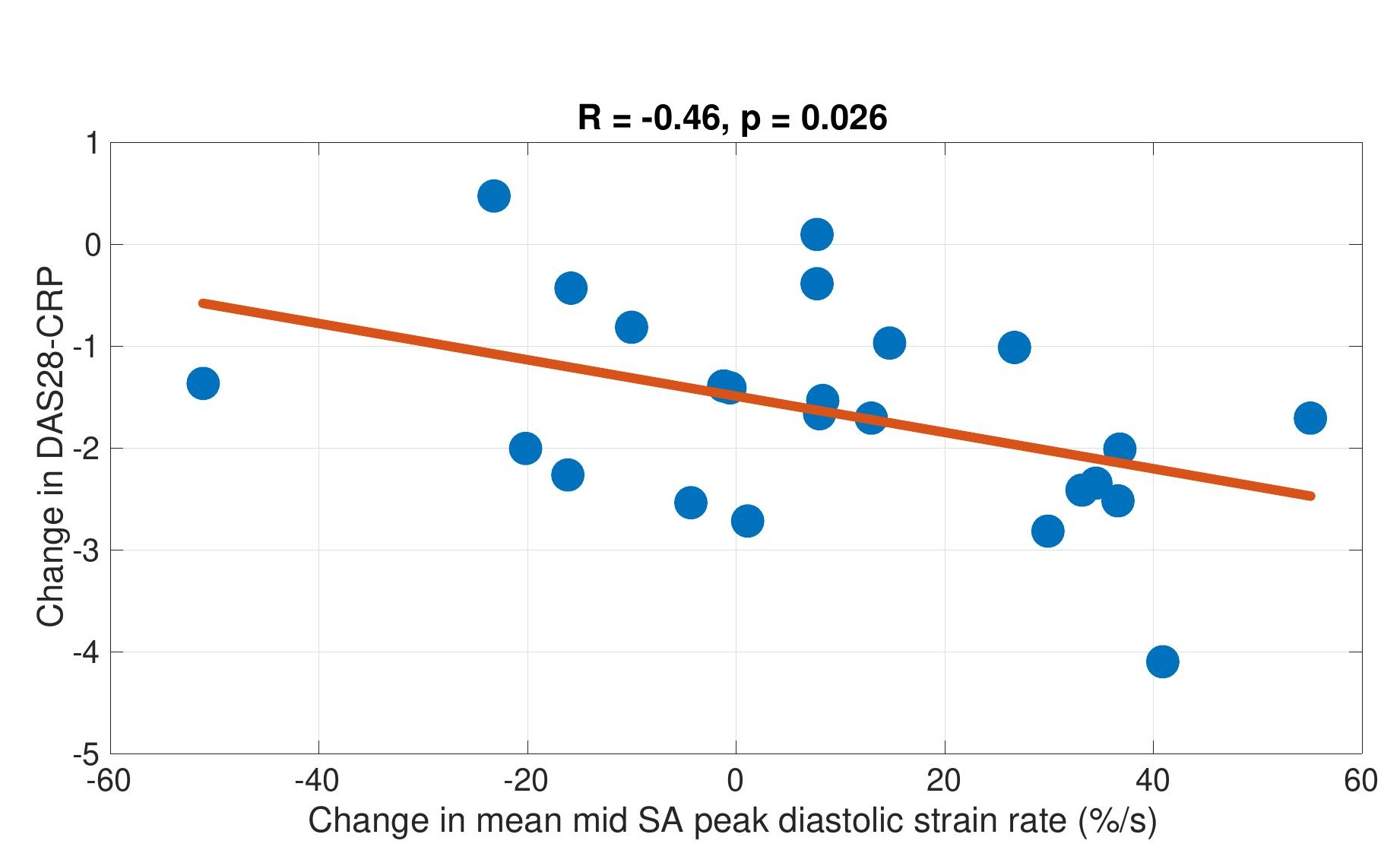

Figure4

Figure

4

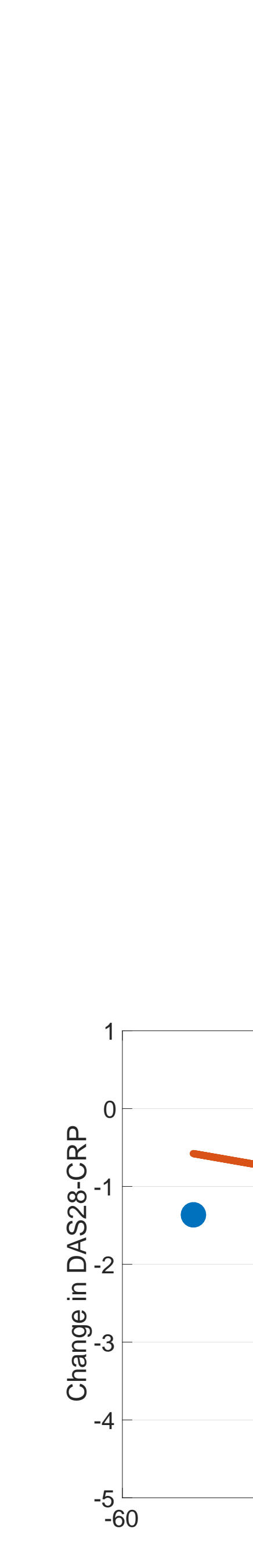

(1)

$\sqrt{2}$

(1)

$\sqrt{2}$
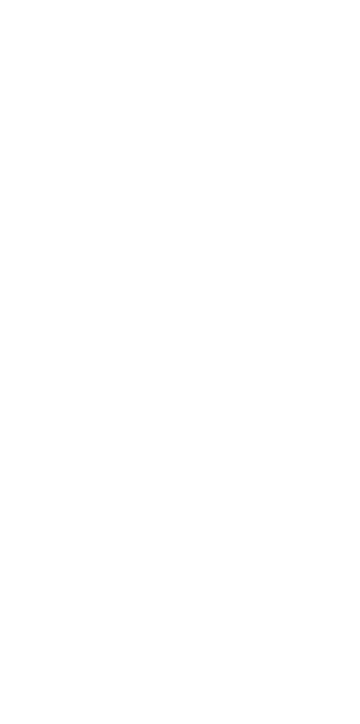
Figure5_left

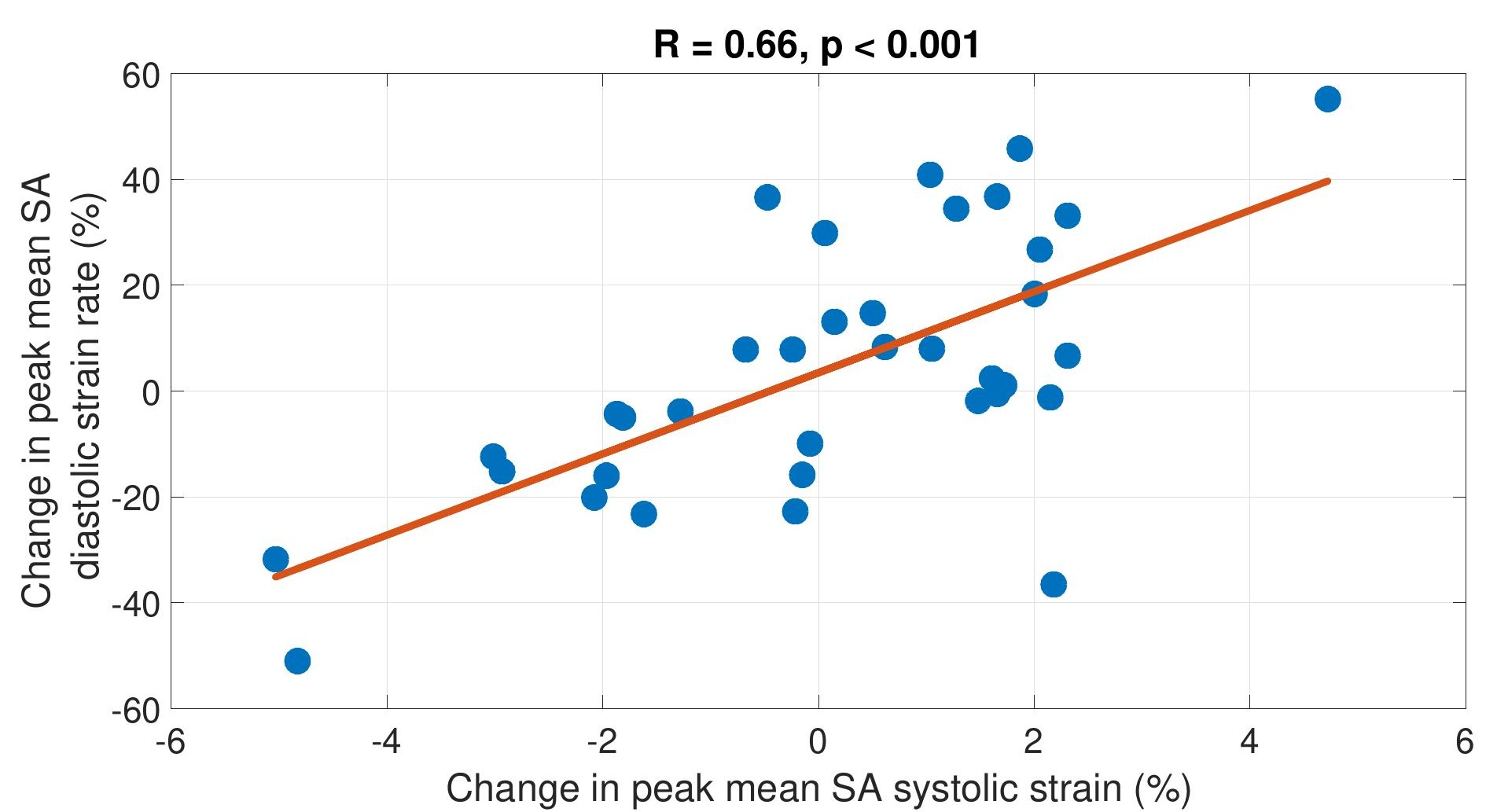

6

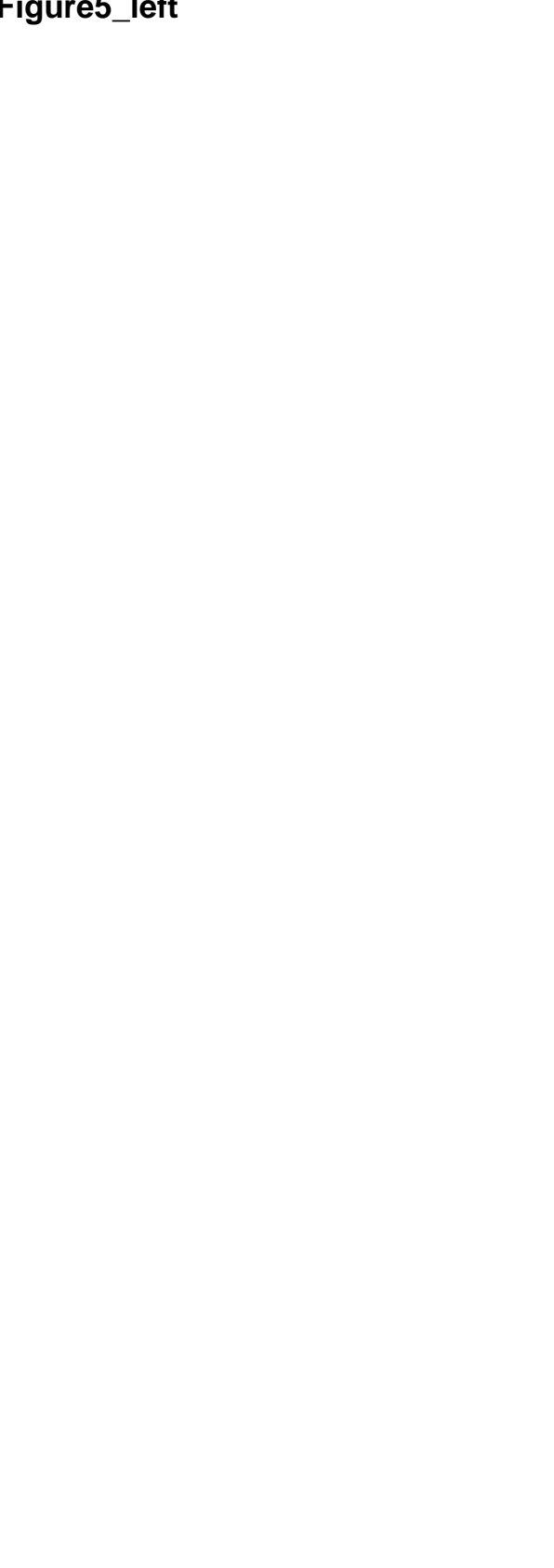

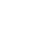
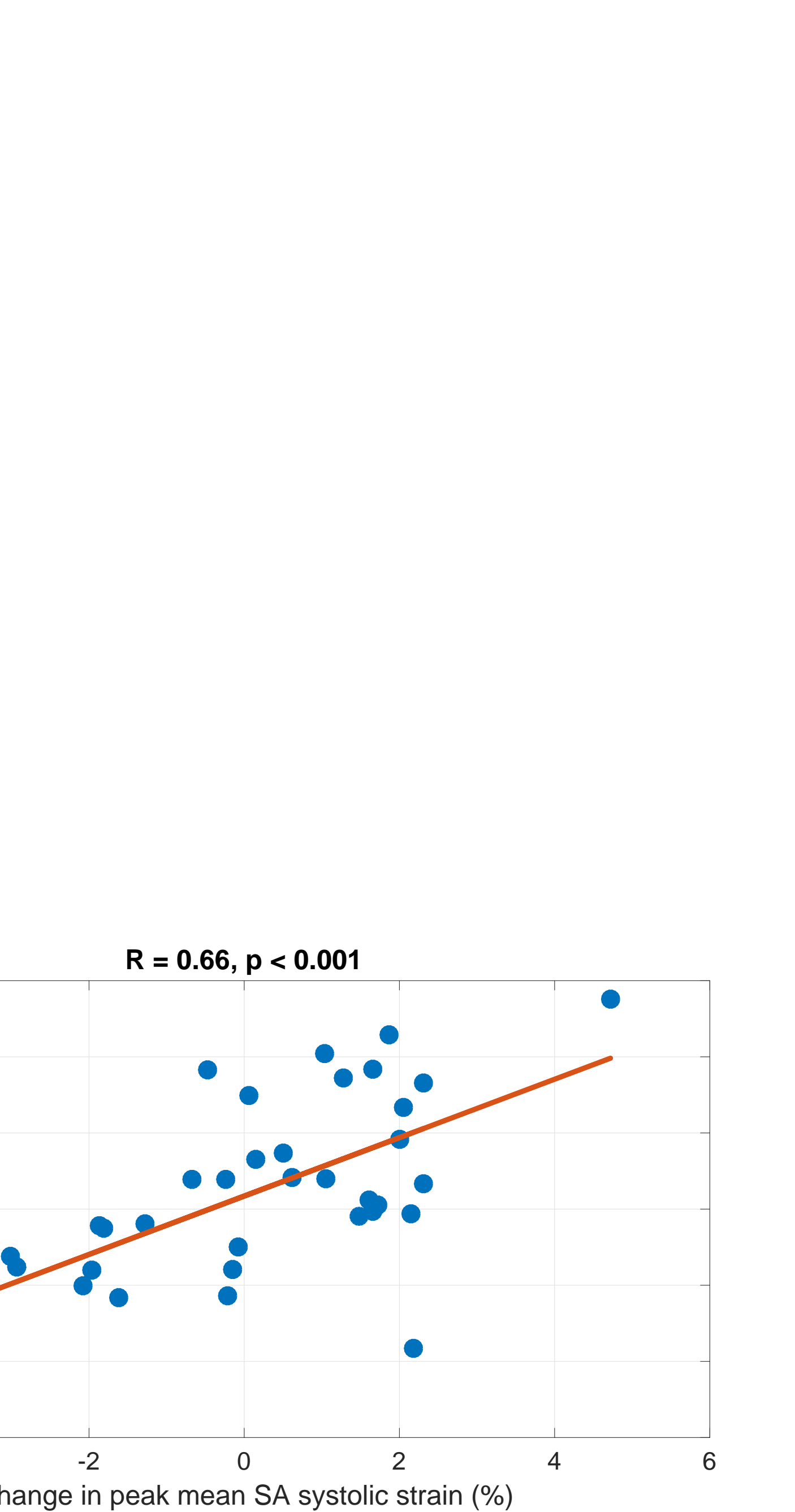
Figure5_right

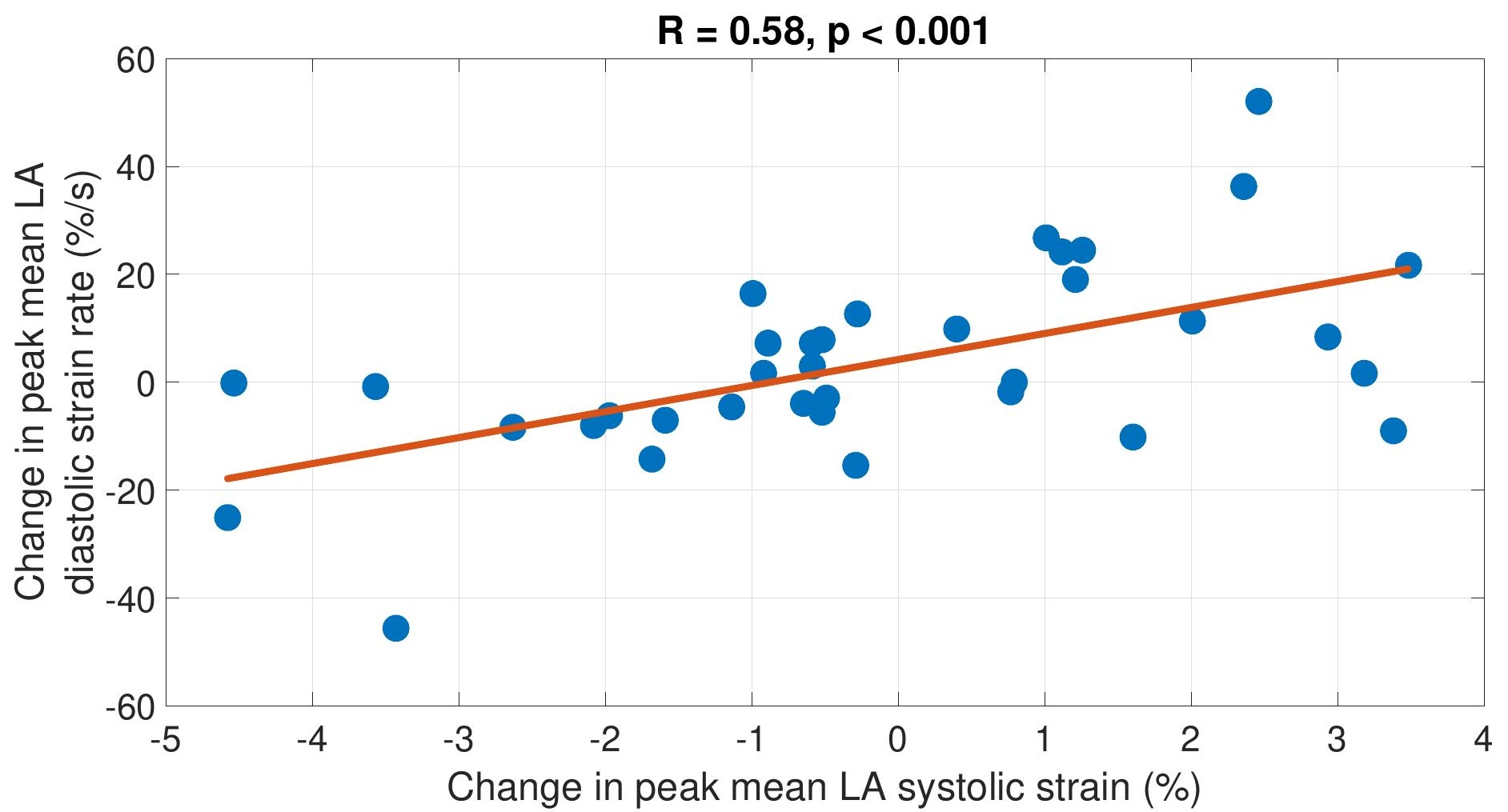




\begin{tabular}{lccc} 
Clinical feature & $\begin{array}{c}\text { Patients with } \\
\text { early RA } \\
(\mathbf{n = 2 5})\end{array}$ & $\begin{array}{c}\text { Patients with } \\
\text { chronic RA } \\
(\mathbf{n = 1 4 )}\end{array}$ & $\begin{array}{c}\text { p-value } \\
\text { (t-test) }\end{array}$ \\
\hline Age (years) & $48 \pm 14$ & $49 \pm 15$ & 0.921 \\
\hline RF positivity; $\mathrm{n}(\%)$ & $22(88 \%)$ & $13(93 \%)$ & 1.000 \\
\hline ACPA positivity; n (\%) & $22(88 \%)$ & $13(93 \%)$ & 1.000 \\
\hline Swollen joints & $8 \pm 6$ & $6 \pm 5$ & 0.296 \\
\hline Tender joints & $8 \pm 8$ & $7 \pm 4$ & 0.549 \\
\hline DAS28-CRP & $3.7 \pm 0.9$ & $3.2 \pm 1.1$ & 0.356 \\
\hline Extra-articular manifestations; $\mathrm{n}(\%)$ & $4(16 \%)$ & $7(50 \%)$ & $0.033 *$ \\
\hline Erosions on radiographs; $\mathrm{n}(\%)$ & $3(13 \%)$ & $11(85 \%)$ & $<0.001^{*}$ \\
\hline Duration of RA symptoms $(\mathrm{months})$ & $11 \pm 15$ & $207 \pm 133$ & $<0.001^{*}$ \\
\hline CRP (mg/l) & $12 \pm 14$ & $6 \pm 6$ & 0.058 \\
\hline LDL (mmol/l) & $2.9 \pm 0.7$ & $3.2 \pm 1.0$ & 0.434 \\
\hline BMI (kg/m $\left.{ }^{2}\right)$ & $23 \pm 4$ & $24 \pm 4$ & 0.518 \\
\hline Waist circumference $(\mathrm{cm})$ & $79 \pm 10$ & $81 \pm 11$ & 0.668 \\
\hline Mean blood pressure $(\mathrm{mmHg})$ & $109 \pm 13$ & $111 \pm 19$ & 0.779 \\
\hline
\end{tabular}




\begin{tabular}{lcccc} 
Volumetric studies & Before treatment & After treatment & Change & p-value \\
\hline BSA $\left(\mathrm{m}^{2}\right)$ & $1.7(1.7-1.8)$ & $1.7(1.7-1.8)$ & 0.0 & 0.742 \\
\hline Mean heart rate $(\mathrm{bpm})$ & $70(66-77)$ & $71(65-79)$ & $2.0(-1.5-5.5)$ & 0.577 \\
\hline LVEDV $\left(\mathrm{ml} / \mathrm{m}^{2}\right)$ & $81(76-90)$ & $83(76-94)$ & $2.0(-4.5-4.0)$ & 0.639 \\
\hline LVESV $\left(\mathrm{ml} / \mathrm{m}^{2}\right)$ & $35(31-40)$ & $33(30-40)$ & $0.0(-3.0-2.0)$ & 0.704 \\
\hline LVEF $(\%)$ & $57(56-60)$ & $57(55-62)$ & $0.0(-1.0-2.0)$ & 0.978 \\
\hline LV mass $\left(\mathrm{mg} / \mathrm{m}^{2}\right)$ & $51(46-57)$ & $54(50-58)$ & $1.0(-2.5-7.5)$ & 0.211 \\
\hline PFR $(1 / \mathrm{s})$ & $1.5(1.3-1.9)$ & $1.7(1.5-2.1)$ & $0.1(0.0-0.2)$ & 0.646 \\
\hline TPFR $(\mathrm{ms})$ & $495(443-561)$ & $441(340-518)$ & $-64(-91-(-33))$ & $0.018^{*}$ \\
\hline DAS28-CRP & $3.8(3.2-4.1)$ & $1.6(1.4-2.2)$ & $-1.7(-2.4-(-1.2))$ & $<0.001^{*}$ \\
\hline
\end{tabular}




\begin{tabular}{lcccc} 
Volumetric studies & Before treatment & After treatment & Change & p-value \\
\hline BSA $\left(\mathrm{m}^{2}\right)$ & $1.7(1.6-1.7)$ & $1.7(1.6-1.7)$ & 0.0 & 0.971 \\
\hline Mean heart rate $(\mathrm{bpm})$ & $75(68-89)$ & $75(67-81)$ & $-2.0(-9.0-5)$ & 0.730 \\
\hline LVEDV $\left(\mathrm{ml} / \mathrm{m}^{2}\right)$ & $81(74-92)$ & $77(72-87)$ & $-2.5(-10.0-0.0)$ & $0.031^{*}$ \\
\hline LVESV $\left(\mathrm{ml} / \mathrm{m}^{2}\right)$ & $32(28-40)$ & $32(25-35)$ & $-1.0(-5.0-0.0)$ & 0.307 \\
\hline LVEF $(\%)$ & $60(58-62)$ & $59(58-64)$ & $0.0(-2.0-2.0)$ & 0.791 \\
\hline LV mass $\left(\mathrm{mg} / \mathrm{m}^{2}\right)$ & $52(45-56)$ & $51(45-56)$ & $0.0(-7.0-4.0)$ & 0.441 \\
\hline PFR $(1 / \mathrm{s})$ & $1.8(1.4-2.2)$ & $1.8(1.5-2.0)$ & $-0.1(-0.4-0.2)$ & 0.952 \\
\hline TPFR $(\mathrm{ms})$ & $433(326-516)$ & $433(393-504)$ & $2.8(-27.8-60.1)$ & 0.670 \\
\hline DAS28-CRP & $3.4(2.3-4.2)$ & $3.0(2.3-3.4)$ & $-0.2(-1.3-0.6)$ & 0.296 \\
\hline
\end{tabular}




\begin{tabular}{|c|c|c|c|c|}
\hline Segment & Before treatment & After treatment & Change & p-value \\
\hline \multicolumn{5}{|c|}{ Peak systolic SA strain (\%) } \\
\hline Anterior & $-21.6(-24.2-(-19.8))$ & $-22.0(-24.8-(-19.4))$ & $0.1(-2.1-1.6)$ & 0.775 \\
\hline Anteroseptal & $-17.0(-19.8-(-15.4))$ & $-17.6(-21.1-(-16.5))$ & $-0.2(-2.6-1.2)$ & 0.753 \\
\hline Inferoseptal & $-15.0(-17.6-(-12.2))$ & $-16.2(-18.5-(-14.4))$ & $-1.1(-2.7-1.2)$ & 0.076 \\
\hline Inferior & $-18.7(-19.9-(-16.4))$ & $-17.5(-22.6-(-15.4))$ & $0.4(-2.2-2.2)$ & 0.886 \\
\hline Inferolateral & $-20.8(-23.9-(-18.7))$ & $-21.6(-23.6-(-15.4))$ & $-0.7(-2.8-1.0)$ & 0.391 \\
\hline Anterolateral & $-19.8(-20.8-(-17.3))$ & $-20.5(-21.9-(-17.1))$ & $0.7(-0.7-2.1)$ & 0.932 \\
\hline Mean & $-18.9(-20.8-(-16.6))$ & $-19.3(-21.3-(-17.0))$ & $-0.4(-1.6-0.8)$ & 0.199 \\
\hline \multicolumn{5}{|c|}{ Peak diastolic SA strain rate $(\% / s)$} \\
\hline Anterior & $82.2(63.3-98.4)$ & $85.5(76.5-109.2)$ & $18.7(3.1-26.4)$ & $0.013^{*}$ \\
\hline Anteroseptal & $82.0(75.8-97.0)$ & $95.8(78.1-102.7)$ & $5.5(-6.7-22.7)$ & 0.159 \\
\hline Inferoseptal & $71.0(64.7-81.3)$ & $79.0(64.6-92.8)$ & $2.2(-7.8-11.5)$ & 0.394 \\
\hline Inferior & $77.2(65.9-97.4)$ & $84.7(67.6-92.8)$ & $2.6(-13.0-21.4)$ & 0.434 \\
\hline Inferolateral & $89.3(83.8-120.8)$ & $103.4(75.6-133.6)$ & $8.0(-21.9-33.3)$ & 0.664 \\
\hline Anterolateral & $76.6(61.3-90.6)$ & $88.7(73.1-105.6)$ & $14.6(-10.1-36.4)$ & 0.092 \\
\hline Mean & $82.3(73.9-90.7)$ & $91.1(77.0-100.1)$ & $7.7(-8.2-23.4)$ & $0.050^{*}$ \\
\hline \multicolumn{5}{|c|}{ Peak systolic LA strain (\%) } \\
\hline Mean & $-15.0(-16.4-(-13.1))$ & $-14.1(-15.6-(-12.6))$ & $0.5(-0.8-1.6)$ & 0.549 \\
\hline \multicolumn{5}{|c|}{ Peak diastolic LA strain rate (\%/s) } \\
\hline Mean & $42.0(32.7-49.1)$ & $43.2(34.9-49.7)$ & $-0.1(-9.1-9.9)$ & 0.670 \\
\hline
\end{tabular}




\begin{tabular}{|c|c|c|c|c|}
\hline Segment & Before treatment & After treatment & Change & p-value \\
\hline \multicolumn{5}{|c|}{ Peak systolic SA strain (\%) } \\
\hline Anterior & $-21.3(-24.5-(-18.8))$ & $-20.5(-23.0-(-18.4))$ & $-0.1(-1.6-4.4)$ & 0.380 \\
\hline Anteroseptal & $-16.6(-18.5-(-13.4))$ & $-17.5(-19.2-(-15.2))$ & $-1.1(-3.0-0.7)$ & 0.204 \\
\hline Inferoseptal & $-14.1(-16.9-(-13.1))$ & $-14.7(-19.6-(-12.2))$ & $-1.4(-2.5-2.9)$ & 0.733 \\
\hline Inferior & $-17.9(-19.7-(-17.0))$ & $-18.3(-20.0-(-16.1))$ & $-0.5(-1.4-1.0)$ & 0.622 \\
\hline Inferolateral & $-20.0(-23.5-(-18.5))$ & $-22.8(-24.1-(-16.5))$ & $-0.1(-3.3-1.6)$ & 0.791 \\
\hline Anterolateral & $-19.6(-21.2-(-17.2))$ & $-17.5(-19.2-(-15.5))$ & $1.8(-2.4-5.8)$ & 0.204 \\
\hline Mean & $-18.1(-19.5-(-17.2))$ & $-19.1(-20.1-(-15.7))$ & $-0.7(-1.9-2.5)$ & 0.733 \\
\hline \multicolumn{5}{|c|}{ Peak diastolic SA strain rate $(\% / \mathrm{s})$} \\
\hline Anterior & $87.0(56.0-104.4)$ & $80.3(65.2-94.7)$ & $-17.7(-24.9-14.2)$ & 0.519 \\
\hline Anteroseptal & $85.7(66.6-101.8)$ & $75.2(63.0-87.7)$ & $-15.0(-32.4-6.5)$ & 0.266 \\
\hline Inferoseptal & $79.5(66.5-99.7)$ & $84.8(53.1-96.6)$ & $-18.4(-35.1-11.8)$ & 0.266 \\
\hline Inferior & $91.4(77.8-97.8)$ & $83.7(76.8-110.6)$ & $-5.8(-13.6-21.4)$ & 0.910 \\
\hline Inferolateral & $91.1(72.3-112.8)$ & $77.5(61.7-92.8)$ & $-10.3(-31.8-7.6)$ & 0.233 \\
\hline Anterolateral & $87.5(68.0-93.7)$ & $81.5(50.8-94.7)$ & $-5.5(-24.4-10.8)$ & 0.622 \\
\hline Mean & $86.7(76.3-94.7)$ & $83.3(61.1-97.8)$ & $-7.2(-17.3-1.3)$ & 0.176 \\
\hline \multicolumn{5}{|c|}{ Peak systolic LA strain (\%) } \\
\hline Mean & $-11.1(-15.6-(-9.9))$ & $-12.7(-16.4-(-8.7))$ & $1.8-1.3)$ & 0.776 \\
\hline \multicolumn{5}{|c|}{ Peak diastolic LA strain rate (\%/s) } \\
\hline Mean & $34.3(27.5-38.7)$ & $35.2(28.5-48.3)$ & $2.3(-6.0-22.9)$ & 0.380 \\
\hline
\end{tabular}




\begin{tabular}{|c|c|c|c|c|c|}
\hline \multirow[t]{2}{*}{ Segment } & & Before treatment & After tre & Change & $\mathrm{p}$-va \\
\hline & \multicolumn{5}{|c|}{ T1 relaxation $(\mathrm{ms})$} \\
\hline \multirow[t]{2}{*}{ Anterior } & $1.5 \mathrm{~T}$ & $980(949-1011)$ & $969(946-996)$ & $-15(-16-(-14))$ & 0.844 \\
\hline & $3 \mathrm{~T}$ & $1126(1116-1139)$ & $1135(1109-1196)$ & $7(-77-35)$ & 084 \\
\hline \multirow[t]{2}{*}{ Anteroseptal } & $1.5 \mathrm{~T}$ & $968(950-1031)$ & $1019(C$ & $-11(-49-28)$ & 0.219 \\
\hline & $3 \mathrm{~T}$ & 1172 & 1146 & $-15(-82-49)$ & 117 \\
\hline \multirow[t]{2}{*}{ Inferoseptal } & $1.5 \mathrm{~T}$ & $6-1043)$ & 1010 & $-21(-66-24)$ & 0.578 \\
\hline & $3 \mathrm{~T}$ & 1162( & 1147 & $-23(-66-11)$ & 0.815 \\
\hline \multirow[t]{2}{*}{ Inferior } & $1.5 \mathrm{~T}$ & 971 & 1004 & $4(-54-62)$ & 0.469 \\
\hline & $3 \mathrm{~T}$ & 1160 & 1148 & $-16(-81-29)$ & 0.532 \\
\hline \multirow[t]{2}{*}{ Inferolateral } & $1.5 \mathrm{~T}$ & 964( & 958 & $-9(-26-9)$ & 1 \\
\hline & $3 \mathrm{~T}$ & $165(1110-1185)$ & $1153(1140-1179)$ & $-53(-69-(-34)$ & 0.148 \\
\hline \multirow[t]{2}{*}{ Anterolateral } & $1.5 \mathrm{~T}$ & $944(934$ & 9911 & $25(-25-74)$ & 0.219 \\
\hline & $3 \mathrm{~T}$ & $16-1149)$ & 1137 & $1(-50-37)$ & 0.833 \\
\hline \multirow[t]{2}{*}{ Mean } & $1.5 \mathrm{~T}$ & $963(953-1011)$ & $989(977-1003)$ & $-4(-39-30)$ & 0.375 \\
\hline & $3 \mathrm{~T}$ & $1159(1143-1166)$ & $1147(1117-1181)$ & $-15(-71-21)$ & 0.669 \\
\hline
\end{tabular}




\begin{tabular}{|c|c|c|c|c|c|}
\hline \multirow[t]{2}{*}{ Segment } & & Before treatment & After treatment & Change & p-value \\
\hline & \multicolumn{4}{|c|}{ T1 relaxation $(\mathrm{ms})$} & \\
\hline \multirow[t]{2}{*}{ Anterior } & $1.5 \mathrm{~T}$ & $1000(977-1019)$ & $982(977-1047)$ & $-20(-24-(-2))$ & 0.906 \\
\hline & $3 \mathrm{~T}$ & $1164(1127-1175)$ & $1096(1084-1108)$ & $-47(-56-(-37))$ & 0.313 \\
\hline \multirow[t]{2}{*}{ Anteroseptal } & $1.5 \mathrm{~T}$ & $1005(970-1042)$ & $1028(1026-1048)$ & $31(29-35)$ & 1 \\
\hline & $3 \mathrm{~T}$ & $1187(1159-1189)$ & $1163(1135-1191)$ & $-10(-52-32)$ & 0.813 \\
\hline \multirow[t]{2}{*}{ Inferoseptal } & $1.5 \mathrm{~T}$ & $1007(973-1028)$ & $997(980-1000)$ & $-7(-28-(-6))$ & 0.570 \\
\hline & $3 \mathrm{~T}$ & $1148(1147-1163)$ & $1154(1138-1171)$ & $7(-9-23)$ & 0.750 \\
\hline \multirow[t]{2}{*}{ Inferior } & $1.5 \mathrm{~T}$ & $1001(996-1010)$ & $1000(987-1010)$ & $-6(-16-(-3))$ & 0.382 \\
\hline & $3 \mathrm{~T}$ & $1178(1139-1192)$ & $1165(1116-1213)$ & $6(-62-74)$ & 1 \\
\hline \multirow[t]{2}{*}{ Inferolateral } & $1.5 \mathrm{~T}$ & $980(976-999)$ & $992(989-995)$ & $33(-8-48)$ & 0.938 \\
\hline & $3 \mathrm{~T}$ & $1168(1147-1197)$ & $1147(1114-1179)$ & $-11(-33-11)$ & 1 \\
\hline \multirow[t]{2}{*}{ Anterolateral } & $1.5 \mathrm{~T}$ & $987(955-996)$ & $999(989-1011)$ & $24(14-29)$ & 0.469 \\
\hline & $3 \mathrm{~T}$ & $1146(1135-1190)$ & $1108(1095-1121)$ & $-16(-25-(-7))$ & 0.813 \\
\hline \multirow[t]{2}{*}{ Mean } & $1.5 \mathrm{~T}$ & $1000(991-1008)$ & $990(989-1014)$ & $6(-2-12)$ & 0.570 \\
\hline & $3 \mathrm{~T}$ & $1154(1147-1184)$ & $1139(1114-1163)$ & $-12(-33-10)$ & 1 \\
\hline
\end{tabular}


Acknowledgments

\section{Acknowledgements}

The authors acknowledge financial support from (1) HUS Medical Imaging Center, (2) Helsinki University Hospital Research Funds, (3) Scandinavian Rheumatology Research Foundation, (4) The Finnish Medical Foundation, (5) Finska Läkaresällskapet and (6) Liv och Hälsa. 
ACPA

ERA

BMI

BSA

CMR

CRA

CRP

bDMARD

csDMARD

DAS28-CRP

DMARD

LA

LDL

LGE

LVEF

LVESV

PFR

Q1

Q3

RA

RF

SA

TPFR anti-citrullinated peptide antibody

early rheumatoid arthritis

body mass index

body surface area

cardiovascular magnetic resonance

chronic rheumatoid arthritis

C-reactive protein

biological disease modifying antirheumatic drug

conventional synthetic disease modifying antirheumatic drug

disease activity score

disease modifying antirheumatic drug

long-axis

low density lipoprotein

late gadolinium enhancement

left ventricle ejection fraction

left ventricle end systolic volume

peak filling rate

first quartile

third quartile

rheumatoid arthritis

rheumatoid factor

short-axis

time to peak filling rate 